Published in final edited form as:

Methods Enzymol. 2009 ; 453: 1-16. doi:10.1016/S0076-6879(08)04001-9.

\title{
Initiation of Autophagy by Photodynamic Therapy
}

\author{
David Kessel $^{*}$ and Nancy L. Oleinick ${ }^{\dagger}$ \\ " Department of Pharmacology, Wayne State University School of Medicine, Detroit, Michigan, USA \\ † Department of Radiation Oncology, Case Western Reserve University, Cleveland, Ohio, USA
}

\begin{abstract}
Photodynamic therapy (PDT) involves the irradiation of photosensitized cells with light. Depending on localization of the photosensitizing agent, the process can induce photodamage to the endoplasmic reticulum (ER), mitochondria, plasma membrane, and/or lysosomes. When ER or mitochondria are targeted, antiapoptotic proteins of the Bcl-2 family are especially sensitive to photodamage. Both apoptosis and autophagy can occur after PDT, autophagy being associated with enhanced survival at low levels of photodamage to some cells. Autophagy can become a cell-death pathway if apoptosis is inhibited or when cells attempt to recycle damaged constituents beyond their capacity for recovery. While techniques associated with characterization of autophagy are generally applicable, PDT introduces additional factors related to unknown sites of photodamage that may alter autophagic pathways. This chapter discusses issues that may arise in assessing autophagy after cellular photodamage.
\end{abstract}

\section{Introduction}

Photodynamic therapy (PDT) is based on the ability of certain photosensitizing agents to localize in malignant cells and tissues. Subsequent irradiation with light corresponding to an absorbance optimum of the photosensitizer leads to an energy-transfer process that results in the conversion of molecular oxygen to a reactive oxygen species (ROS) termed singlet oxygen. The highly reactive singlet oxygen oxidizes cellular molecules, usually nearby lipids and proteins. If sufficient drug and light are provided, this can result in a severe oxidative stress in the cells and a very selective means for tumor eradication (Dougherty et al., 1998). Additional ROS may also be formed, including superoxide anion radical, hydrogen peroxide, and hydroxyl radical, any of which can have adverse effects on cellular functions.

Autophagy has been identified as a mode of cell death after PDT and may predominate where apoptosis is unavailable (Buytaert et al., 2006, 2008; Kessel et al., 2006; Xue et al., 2007). Antiapoptotic proteins of the Bcl-2 family, located in the mitochondria and/or endoplasmic reticulum (ER), are among the most sensitive targets for many commonly used photosensitizing drugs (Kim et al., 1999; Xue et al., 2001a). Loss of such proteins can be a trigger for both apoptosis and autophagy (Pattingre et al., 2005). When lysosomes are targeted, PDT leads to the release of lysosomal enzymes, thereby catalyzing the conversion of Bid to the proapoptotic cleavage product termed t-Bid (Reiners et al., 2002). Because of the involvement of lysosomes in the autophagic process, this can have additional implications (i.e., in the fusion of autophagosomes with lysosomes).

Autophagy can be a factor in PDT at two points in the sequence of events. The first involves the ability of autophagy to repair photodamaged cellular components, including organelles. This can result in a loss of the shoulder on the dose-response curve, generally taken to indicate damage repair (Fig. 1.1). Silencing of the autophagy gene designated Atg7 results in the photosensitization of mouse leukemia L1210 cells to photodynamic effects (Kessel and Arroyo, 2007). A similar finding was recently reported with respect to effects of the silencing 
of other factors involved in autophagy on the lethality of ionizing radiation (Apel et al., 2008). However, in human breast cancer MCF-7 cells, silencing of Atg7 may make the cells more resistant to PDT (L.Y. Xue, S.M. Chiu, S. Joseph, and N.L. Oleinick, unpublished).

An additional concern in the context of PDT is the propensity of most photosensitizing agents to migrate to relatively hydrophobic intracellular sites (i.e., membranes). Irradiation may therefore result in the inactivation of proteins required for the autophagic process.

\section{Photosensitizing Agents}

Several photosensitizing agents have been approved for clinical use, and many others are in clinical and preclinical trials. The agents are not always commercially available. Common porphyrins and phthalocyanines can be obtained from the major suppliers (e.g., SigmaAldrich). A large selection of porphyrins, phthalocyanines, and related compounds is available from Frontier Science (Logan, Utah; an inventory can be seen at the website www.info@ frontiersci.com). Frontier Science can often provide a custom preparation of almost any agent whose structure and synthetic route has been published. Photosensitizers prepared for clinical trials or those received directly from a synthetic chemist are generally supplied at a documented high level of purity; those from commercial sources may require additional purification. The majority of the agents in current use are porphyrins, porphyrinderived compounds (e.g., benzoporphyrins or pheophorbides), or related types of macrocycle structures (e.g., phthalocyanines). All contain hydrophobic ring systems, even the nonporphyrin photosensitizers (e.g., hypericin). Structures of the latter compound, the porphyrin skeleton and the porphycene CPO are shown in Fig. 1.2.

The concentration and time of incubation will vary as a function of hydrophobicity. Agents at the extreme ends of the solubility spectrum often require extended loading incubation times (Table 1.1). For delivery to cells, the hydrophobic photosensitizers are generally dissolved in a biocompatible organic solvent, such as ethanol, dimethylformamide or DMSO, or in water containing low $(0.1 \%)$ concentration of a detergent such as Tween 80 , and a small aliquot of the stock solution is added to the serum-containing medium bathing the cells. It is necessary to check that the vehicle is not toxic, but if the level of organic solvent remains below $0.1 \%$ of the medium volume, we have found no effect from it. Entry of the photosensitizers into the cells involves partitioning of the compounds to intracellular hydrophobic sites; there is little evidence for other mechanisms of cellular uptake.

While there are reports in the literature concerning sites of localization of different photosensitizing agents (e.g., Kessel et al., 1997; Trivedi et al., 1999; Lam et al., 2001; Usuda et al., 2003; Buytaert et al., 2006), it is usually necessary for each cell line to be evaluated with regard to these properties. Because the photosensitizers are not directed to specific receptors, and because the structural requirements for localization patterns have not been established for any class of photosensitizers, what applies for one or a few cell lines may not necessarily be pertinent to others.

\section{Additional Factors Unique to PDT}

Unlike conventional drug-treatment protocols, photodynamic effects occur only when photosensitized cells are irradiated. It may be necessary to incubate cells for several hours so as to obtain a sufficient intracellular concentration of the photosensitizing agent (Table 1.1), but formation of ROS will occur only when irradiation begins. To mimic physiological conditions, irradiation is often carried out at $37^{\circ} \mathrm{C}$, but by manipulating the temperature of irradiation, it is possible to alter the immediate consequences. For example, after Bcl-2 photodamage, insertion of Bax into mitochondria occurs only when the temperature is greater that $15{ }^{\circ} \mathrm{C}$ (Pryde et al., 2000). It is therefore possible to carry out irradiation at a temperature 
$<15^{\circ} \mathrm{C}$ so as to prevent the immediate initiation of apoptosis. If a chilled microscope stage is used for observations, it is then feasible to observe mitochondrial or ER photodamage before the initiation of apoptosis (Kessel and Castelli, 2001). This type of strategy can be important in identifying early events in PDT, as apoptosis causes drastic changes in cell morphology. This may also be true with regard to autophagy.

\section{A Typical PDT Protocol}

While the precise conditions may vary, a procedure for photosensitization and irradiation of cells in suspension culture using CPO involves the following steps (a modified protocol for cells that grow attached to a substratum is provided in the section labeled "Dose-response data"):

1. Cells are collected in the exponential phase of growth and suspended in fresh growth medium at a density of $3.5 \times 10^{5}$ per ml, with $20 \mathrm{~m} M$ HEPES, pH 7.0, replacing $\mathrm{NaHCO}_{3}$ to permit maintenance of a near-neutral $\mathrm{pH}$.

2. Cells are loaded with $\mathrm{CPO}$ (final concentration $2 \mu \mathrm{M}$ ) for $30 \mathrm{~min}$ at $37^{\circ} \mathrm{C}$, then collected by centrifugation $(100 \times g, 30 \mathrm{~s})$ and resuspended in fresh HEPES-buffered growth medium containing $10 \%$ serum, at $10^{\circ} \mathrm{C}$.

3. A photosensitized cell suspension is placed in a 1-ml glass tube in a thermoelectrically cooled Petri dish $\left(10^{\circ} \mathrm{C}\right)$ and irradiated with light corresponding to the longwavelength absorbance bands of CPO as defined by a broad-band $600 \pm 30 \mathrm{~nm}$ interference filter. The precise time will depend on prior experiments that establish a dose-response curve on the basis of clonogenic viability studies. With the murine leukemia L1210 cell line, a 2-min irradiation is required.

4. Photodamaged cells can then be used directly for an estimate of photodamage assessed by fluorescence microscopy using fluorescent probes (Kessel and Reiners, 2007) or incubated for $10-60 \mathrm{~min}$ at $37^{\circ} \mathrm{C}$ with the cells subsequently used for the determination of autophagic and/or apoptotic effects (e.g., DEVDase activation, LC3 processing, or vacuole formation detected by phase-contrast and electron microscopy).

5. With adhering cells, a similar protocol is followed except that cells are grown on 1.5$\mathrm{cm}$ circular glass disks and incubated in small Petri dishes throughout.

6. We routinely establish viability by plating appropriate dilutions of cells on soft agar and permitting colonies to develop over 6-10 days. When this is done, sterile techniques are employed throughout.

7. Pellets containing $2.5 \times 10^{6}$ cells are lysed in $100 \mu \mathrm{l}$ of a mixture of $10 \mathrm{~m} M \mathrm{HEPES}$, $\mathrm{pH} 7.5,130 \mathrm{~m} M \mathrm{NaCl}, 1 \%$ Triton $\mathrm{X}-100,10 \mathrm{~m} M \mathrm{NaF}, 10 \mathrm{~m} M$ Na pyrophosphate and $1 \mathrm{~m} M$ PMSF. After $10 \mathrm{~min}$ at $4{ }^{\circ} \mathrm{C}$, the mixture is clarified by brief centrifugation $(10,000 \times g, 3 \mathrm{~min})$. The protein content is determined on a $10 \mu \mathrm{l}$ aliquot and the remainder used for assays (e.g., caspase activity or LC3 processing).

\section{Identification and Characterization of Autophagy after PDT}

Identification of autophagy can be ambiguous. No kits are available for qualitative or quantitative analysis. Some techniques that have proven useful are outlined subsequently.

\subsection{Phase-contrast microscopy}

At intervals following irradiation, cells are inspected for vacuole formation using phasecontrast microscopy. While this cannot be considered an unambiguous procedure, the appearance of such vacuoles (compared to a control culture that is irradiated without the 
photosensitizer) is often associated with an autophagic response (Buytaert et al., 2006; Kessel and Arroyo, 2007; Kessel and Reiners, 2007; Kessel et al., 2006).

\subsection{Fluorescence microscopy}

Adequate image acquisition can be carried out with any conventional fluorescence microscope. We have successfully used the Nikon Eclipse E600 system with Plan fluor objectives specifically designed for fluorescence detection. This is an upright system but can be used to examine adhering cells if coverslips are placed in the dishes being used for cell culture.

It is helpful to have phase rings incorporated into the objectives so that both phase-contrast and fluorescence images can be obtained. We have also used a Plan Apo 60X water immersion objective. This has the advantage of using water rather than oil so that there is less drag on the cover slip when acquiring a Z-series of images. This procedure is helpful in assessing numbers of lysosomes, or acidic vesicles. Use of a Nikon Apo 60X objective enhances resolution of images. This objective does not contain a phase ring, improving sensitivity to fluorescence, but eliminating the possibility for comparing phase with fluorescence images.

\subsection{Techniques in fluorescence microscopy}

A qualitative estimate of initiation of autophagy after PDT can be obtained by examining the subsequent appearance of vesicles labeled with monodansylcadaverine (MDC) or any of the LysoTracker or LysoSensor probes provided by Molecular Probes/Invitrogen (Eugene, OR). In a typical study, cells are labeled with $10 \mu \mathrm{MMC}$ for $10 \mathrm{~min}$ at $37^{\circ} \mathrm{C}$, and patterns of punctate green fluorescence determined using 360-380 nm excitation and 520-560 nm emission (also see the chapter by Vázquez and Colombo in this volume). There is some controversy in the literature as to whether this is (Iwai-Kanai et al., 2008) or is not (Bampton et al., 2005) a suitable test for autophagy.

Enhanced numbers of lysosomes or other acidic vesicles can be visualized using one of the LysoTrackers or LysoSensors provided by Molecular Probes. Incubation for 5 min at $37{ }^{\circ} \mathrm{C}$ is usually sufficient for labeling of L1210 cells in suspension culture using $100 \mathrm{n} M$ of LysoTracker Red or $100 \mathrm{n} M$ of the LysoSensors. Of the probes in current use, we have tested LysoTracker Red $\left(\lambda_{\mathrm{ex}}=570 \mathrm{~nm}, \lambda_{\mathrm{em}}=590 \mathrm{~nm}\right)$, LysoSensor Yellow $\left(\lambda_{\mathrm{ex}}=465 \mathrm{~nm}, \lambda_{\mathrm{em}}=535\right.$ $\mathrm{nm})$, and LysoSensor Green $\left(\lambda_{\mathrm{ex}}=440 \mathrm{~nm}, \lambda_{\mathrm{em}}=505 \mathrm{~nm}\right)$. Although the latter probes have a greater Stokes shift, any of these probes is satisfactory for assessing relative numbers of lysosomes and other acidic vesicles. It may be feasible to obtain more quantitative data using flow cytometry.

To improve the quantitation of labeling patterns, a fluorescence microscope with a Z-drive is useful. A confocal microscope will eliminate out-of-plane emissions, allowing both sharper images and the ability to visualize a series of optical planes through the cells using the Z-drive. This permits acquisition of a series of stacked images, with subsequent image processing capable of resolving numbers of fluorescent loci. The Metamorph software contains a program for selecting the in-focus pixels from a stack of images. Alternatively, removal of blur from out-of-focus pixels can be better accomplished with AutoQuant software (AutoQuant Imaging, Troy, NY). This can offer an improved assessment of MDC or LysoTracker fluorescence.

To date, we have only limited experience using GFP-labeled LC3, a procedure that has been successful in other contexts (Klionsky et al., 2008). Preliminary studies suggest that a substantial increase in appearance of punctate fluorescence is associated with other indices of autophagy after photodamage. 


\subsection{Electron microscopy}

Electron microscopy provides an estimate of the nature of vacuoles associated with PDT. For this purpose, cells are fixed with $2.5 \%$ glutaraldehyde in phosphate-buffered saline, and stored for processing (also see the chapter by Ylä-Anttila et al., in this volume). It is important to include treatment with uranium acetate and lead citrate for optimal visualization of the doublemembrane structure associated with autophagy. A guide to interpretation of data has been reported (Eskelinen, 2008). The major problems to consider are that (1) supralethal light doses can obliterate most cellular structures (something that can also be visualized by phase-contrast microscopy), and (2) it is important to examine a population of control cells to assess the level of autophagy in the normal cell population. In MCF-7 cells, a large increase in the content of autophagosomes was observed following PDT (Xue et al., 2007). Typical results are as shown in Fig. 1.3.

\subsection{Western blots: LC3 processing}

Western blots as an index of LC3 processing have proved useful for providing a semiquantitative indication of autophagy, if appropriate precautions are taken (Mizushima and Yoshimori, 2007) (also see the chapter by Kimura et al., in this volume). A useful, but sometimes neglected procedure for assessing the autophagic flux involves carrying out experiments in the presence versus absence of lysosomal protease inhibitors (e.g., E64d and acetyl pepstatin). With the murine L1210 leukemia cells, where autophagy can be detected within 30-60 min after photodamage, these inhibitors can be added during the sensitizerloading incubation. If longer intervals are required, it will be necessary to determine that the inhibitors are still active during the process and/or have not induced toxic responses by themselves. Perhaps additional supplements will be required. This procedure is found to provide an indication of autophagy after ER photodamage to L1210 cells (Kessel and Arroyo, 2007). However, in MCF-7 cells, the inhibitors cause extensive accumulation of LC3-II independent of PDT and do not alter the level of LC3-II that accumulates in the cells in response to PDT (Xue et al., 2007). Thus, in this latter case, it is possible that both the inhibitors and PDT with the photosensitizer Pc 4 block autophagy at the same late stage of proteolysis following fusion of autophagosomes with lysosomes.

\section{Effects of Autophagy on PDT Responses}

\subsection{Dose-response data}

In the context of PDT, the simplest method for altering the dose is to vary the light intensity or duration. Under these conditions, a dose-response curve can be generated and effects of autophagy most readily observed by use of appropriate knockouts. Another simple method for altering the dose is to vary the amount of the photosensitizer in the cell culture medium, allowing sufficient time for cell uptake of the photosensitizer to reach a maximum level. In such a protocol, all of the cultures would then receive the same light dose. In either case, an appropriate measure of overall cell killing is required. A variety of short-term assays of cell viability, such as uptake of vital dyes (e.g., trypan blue) or determination of the ability of cell mitochondria to reduce a tetrazolium dye to a colored product (e.g., MTT assay), are often used because of their relative simplicity and ease. We prefer to avoid these assays whenever possible, as none give a total accounting of cell deaths, both immediate and delayed. Colony-forming assays provide the most reliable assessment of the percentage of cells in a population that are capable of dividing indefinitely and forming a colony. Moreover, short-term assay results can be misleading (Xue et al., 2001a).

There are two types of clonogenic assay used for adhering cells, each of which has advantages and disadvantages. We call these preplate and postplate protocols. In the former, small numbers of cells (e.g., 100, 300, 1,000) are plated in tissue-culture dishes (60-mm diameter) and allowed 
to attach to the substratum. This usually requires approximately $4 \mathrm{~h}$. The cells in some of the dishes are exposed to the photosensitizer and light, while other dishes receive photosensitizer only, light only, or no treatment. Then the dishes are returned to the incubator for 1-2 weeks to allow colony formation. In the postplate protocol, cells are treated while in exponential growth or after they have reached confluence. Cultures are exposed to PDT or are designated controls, and then the cells from each plate are recovered by trypsinization, counted, and replated in multiple plates in sufficient number to yield 50-100 colonies. This number is chosen to allow accurate counting of individual colonies while providing statistical significance. The advantage of the preplate protocol is its comparative simplicity. However, a serious disadvantage is that the extent of uptake of the photosensitizer into the small number of cells plated may be quite different from that into each cell in a subconfluent culture. As a result, the toxicity measured with the preplate protocol may not reflect the toxicity under the same conditions in which most molecular studies (e.g., LC3 processing) are carried out. In contrast, in the postplate protocol, identical cultures may be exposed to PDT, then processed for colony formation or molecular measurements. However, it has been observed occasionally that monolayer cultures subjected to some PDT protocols can become so firmly attached to the substrate by PDT that it is not possible to remove them with trypsin (Ball et al., 2001; Uzdensky et al., 2004). If this occurs, the postplate protocol cannot be carried out with that combination of cells, photosensitizer, and dose. In most cases, this is not a problem, and because any number of cells up to $10^{6}$ may be plated to determine colony formation, it is possible to determine if the treatment has left as little as 1 live cell out of a million treated. Because this is the method we advocate, the procedure will be described in more detail.

\subsection{A protocol for determining the effect of PDT on the colony-forming ability of adhering cultures}

1. Setting up the cultures. Sterile technique is used for steps $1-5$. A series of T-25 flasks is inoculated with sufficient cells to yield replicate subcon-fluent cultures on the planned day of the experiment (day 0). As an example, for MCF-7 cells, we routinely inoculate $\approx 7 \times 10^{5}$ cells into each of 10-20 T-25 flasks 2 days before the day of PDT (i.e., on day -2). These cultures are allowed to grow in a tissue culture incubator at $37{ }^{\circ} \mathrm{C}$ in a humidified atmosphere of $5 \% \mathrm{CO}_{2}$ in air. When used for the PDT experiment on day 0 , there are approximately $210^{6}$ cells in each flask.

2. Adding the photosensitizer. On day -1 , an aliquot of a photosensitizer stock solution is added to the medium above the cell monolayer. The timing of photosensitizer addition and dose are determined in preliminary experiments. Issues concerning solvents for hydrophobic photosensitizers have been discussed previously.

3. Photoirradiation. Flasks are exposed one at a time to the desired wavelengths of light appropriate for the photosensitizer at the light fluence(s) and fluence rate(s) to be studied. We typically use an LED array with a peak output at $675 \mathrm{~nm}$, which is chosen because it is close to the absorption maximum of phthalocyanines, but broad-band light sources with suitable filters can also be used, as discussed previously.

4. Recovery of cells from the monolayer. Following irradiation, the cells from each culture are released from the monolayer by trypsinization $(1 \mathrm{~mL}$ of $0.25 \%$ trypsinEDTA purchased from Thermo Scientific, South Logan, UT). The trypsin is blocked by addition of $4 \mathrm{~mL}$ of serum-containing medium, and the cell suspension is pipetted several times to break cell clumps. The presence of single cells is checked under a microscope.

5. Processing of cells for colony formation. An aliquot of the cells is counted, either with an electronic cell counter or a hemacytometer, and the initial cell density is calculated. Serial dilutions of the cell stock are made into medium such that the final dilution will 
result in the desired number of cells being delivered to each of at least $360-\mathrm{mm}$ tissueculture dishes. Calculation of that number requires knowing the plating efficiency (PE; the number of colonies formed per 100 cells plated) of the untreated cells from preliminary tests. For many human cancer cell lines, the PE is $20 \%-50 \%$, whereas for many rodent cell lines, the PE can be $80 \%$ or greater. For example, for a cell line that has a PE of $25 \%$, if 400 cells are plated, 100 colonies should be obtained. For a culture that was exposed to a dose of PDT that is expected to kill $90 \%$ of the cells, 4000 cells should be plated in each dish to result in 100 colonies. If the expected survival is not known, it may be necessary to plate, for the example given, 3 dishes of 4000 cells, 3 with half and 3 with double that number. All dishes are placed in an incubator and left undisturbed (generally $1-2$ weeks) to allow observable individual colonies to form.

6. Determination of the survival response. The medium is removed, and the monolayer is covered with approximately $2 \mathrm{~mL}$ of a $0.1 \%$ crystal violet in $20 \%$ ethanol, and after approximately $5 \mathrm{~min}$ to allow staining of the cells, the dishes are washed by gentle immersion into a tub of cool water. The plates are turned upside down to drain and dry. The colonies are then counted by eye under a dissecting microscope or magnifying glass. For each dish, the number of colonies containing at least 50 cells is divided by the number of cells plated to determine the PE. The PE values of triplicate dishes are averaged and normalized to the PE of the controls.

\subsection{Role of autophagy in the sensitivity of cells to PDT}

Use of siRNA to produce a significant decrease in Atg7 reveals that autophagy can be a survival process at the lower end of the dose-response curve in mouse leukemia L1210 cells (Kessel and Arroyo, 2007; Kessel and Reiners, 2007). In contrast, MCF-7 human breast cancer cells deficient in Atg7 (Abedin et al., 2006) are more resistant to the lowest doses of PDT, as revealed by an increased shoulder on the clonogenic survival curve (L.Y. Xue, S.M. Chiu, S. Joseph, and N.L. Oleinick, unpublished). Some investigators have advised use of different knockouts (e.g., comparing Atg7 with Atg5) to determine whether a process unique to one of the gene products might skew the results. The cell type-and/or agent-dependence of cell responses to loss of Atg7 is also observed with Atg5 knockdown. Thus, murine embryonic fibroblasts (MEFs) deficient in Atg5 are more sensitive to treatment with staurosporine or tunicamycin but more resistant to treatment with menadione or UVC-radiation than the Atg5-replete MEFs (Wang et al., 2008), and SK-N-SH neuroblastoma cells deficient in Atg5 are sensitized to cell death, as compared with wild-type cells, when treated with ER stressors but not when treated with staurosporine or when pretreated with rapamycin to inhibit mTOR activity (Ogata et al., 2006). Clearly, the mechanisms and roles of autophagy following PDT could also differ markedly in different cell types, depending on a variety of cell characteristics, including their propensity to undergo apoptosis, and in response to agents that produce different types or locations of damage. For PDT, this means that different responses may also follow treatment with photosensitizers that localize to different organelles.

\subsection{Sequence of events}

Autophagy is expected to occur at a minimum of two points in the cellular response to photodamage. When the ER and/or mitochondria are targets for photodamage, the first response occurs shortly after irradiation of photosensitized L1210 cells (Kessel and Arroyo, 2007). Autophagic vacuoles are observed within 15 min after irradiation, presumably associated with the recycling of photodamaged organelles. A second phase of autophagy occurs after the apoptotic response is ending and may reflect the fate of cells that attempt an excessive amount of recycling and cannot survive. After $24 \mathrm{~h}$, there are a few survivors along with highly vacuolated cells that are freely permeably to propidium iodide. Phase-contrast images showing 
the appearance of autophagic vacuoles and apoptotic morphology after an $\mathrm{LD}_{90}$ PDT dose are shown in Fig. 1.4. As with the many other measures, the same sequence of events is extended over a longer time period in carcinoma cells than in the leukemic cells (Xue et al., 2007). In human breast cancer MCF-7 cells, substantial increases in LC3-II can be observed by 2-24 h after PDT (Fig. 1.5). This may indicate that PDT is promoting the early stage of apoptosis but interfering with the later stages of autophagosome processing or LC3-II degradation.

\subsection{Apoptosis versus autophagy}

The murine L1210 cell line is useful for the study of apoptosis $v s$. autophagy as cell death mechanisms. Silencing the Atg7 gene appears to essentially abolish autophagy, whereas loss of Bax is sufficient to substantially decrease apoptosis (Kessel and Arroyo, 2007). Figure 1.6 shows the relative response of this cell line to $90 \%$ photokilling with the porphycene CPO. One hour after irradiation, a few apoptotic cells are detected with HO33342, and some vacuoles are apparent. When Atg7 is silenced, there is a much more substantial apoptotic response, while loss of Bax results in a substantially greater number of vacuoles. In studies from the Kessel laboratory cited previously, vacuolization in this cell line is accompanied by LC3 processing, together with the appearance of double-membranes observed by electron microscopy.

Processing of LC3 appears to occur in all of the cell types that have been examined following PDT (Buytaert et al., 2006; Kessel et al., 2006; Xue et al., 2007). Buytaert et al. (2006) found greater levels of PDT-induced LC3-II in Bax/Bak-double knockout MEFs that are deficient in apoptosis than in either the same cells transfected with mitochondrion-directed Bax (where the ability to undergo apoptosis is restored) or in apoptosis-competent wild-type MEFs. Although data for only one PDT dose and one post-PDT time are reported, the results suggest that the autophagic response in this system is greater when apoptosis is defective. In contrast, in a comparison of procaspase-3-deficient versus procaspase-3-overexpressing MCF-7 cells (Xue et al., 2007), there is no marked difference in the rate or extent of accumulation of LC3-II, suggesting that the initiation of autophagy is independent of the ability of the cells to undergo apoptosis. However, apoptosis dominates as a mechanism of cell death in those cells having a fully constituted apoptotic pathway, whereas a non-apoptotic pathway, possibly autophagy, is responsible for cell death when apoptosis is compromised (Xue et al., 2007). Furthermore, as there is the potential for cross talk between the two pathways (e.g., via the interaction of Beclin 1 with Bcl-2), further research is needed to explore more fully the relationship between apoptosis and autophagy following PDT.

\section{Acknowledgments}

The authors' research is supported by NIH grants R01 CA83917, R01 CA106491, P30 CA43703, and CA 23378 from the National Cancer Institute, DHHS, and by the State of Ohio Biomedical Research and Technology Transfer Trust TECH 05-063.

\section{REFERENCES}

Abedin MJ, Wang D, McDonnell MA, Lehmann U, Kelekar A. Autophagy delays apoptotic death in breast cancer cells following DNA damage. Cell Death Differ 2006;14:500-510. [PubMed: 16990848]

Apel A, Herr I, Schwarz H, Rodemann HP, Mayer A. Blocked autophagy sensitizes resistant carcinoma cells to radiation therapy. Cancer Res 2008;68:1485-1494. [PubMed: 18316613]

Ball DJ, Mayhew S, Vernon DI, Griffin M, Brown SB. Decreased efficiency of trypsinization of cells following photodynamic therapy: Evaluation of a role for tissue transglutaminase. Photochem. Photobiol 2001;73:47-53. [PubMed: 11202365]

Bampton ET, Goemans CG, Niranjan D, Mizushima N, Tolkovsky AM. The dynamics of autophagy visualized in live cells: From autophagosome formation to fusion with endo/lysosomes. Autophagy 2005;1:23-36. [PubMed: 16874023] 
Buytaert E, Callewaert G, Hendrickx N, Scorrano L, Hartmann D, Missiaen L, Vandenheede JR, Heirman I, Grooten J, Agostinis P. Role of endoplasmic reticulum depletion and multidomain proapoptotic BAX and BAK proteins in shaping cell death after hypericin- mediated photodynamic therapy. FASEB J 2006;20:756-758. [PubMed: 16455754]

Buytaert E, Matroule JY, Durinck S, Close P, Kocanova S, Vandenheede JR, de Witte PA, Piette J, Agostinis P. Molecular effectors and modulators of hypericin-mediated cell death in bladder cancer cells. Oncogene 2008;27:1916-1929. [PubMed: 17952126]

Dougherty TJ, Gomer CJ, Henderson BW, Jori G, Kessel D, Korbelik M, Moan J, Peng Q. Photodynamic therapy. J. Natl. Cancer Inst 1998;90:889-905. [PubMed: 9637138]

Eskelinen E-L. To be or not to be? Examples of incorrect identification of autophagic compartments in conventional transmission electron microscopy of mammalian cells. Autophagy 2008;4:257-260. [PubMed: 17986849]

Iwai-Kanai E, Yuan H, Huang C, Sayen MR, Perry-Garza CN, Kim L, Gottlieb RA. A method to measure cardiac autophagic flux in vivo. Autophagy 2008;4:322-329. [PubMed: 18216495]

Kessel D, Arroyo AS. Apoptotic and autophagic responses to Bcl-2 inhibition and photodamage. Photochem. Photobiol. Sci 2007;6:1290-1295. [PubMed: 18046484]

Kessel D, Castelli M. Evidence that bcl-2 is the target of three photosensitizers that induce a rapid apoptotic response. Photochem. Photobiol 2001;74:318-322. [PubMed: 11547571]

Kessel D, Luo Y, Deng Y, Chang CK. The role of subcellular localization in initiation of apoptosis by photodynamic therapy. Photochem. Photobiol 1997;65:422-426. [PubMed: 9077123]

Kessel D, Reiners JJ Jr. Apoptosis and autophagy after mitochondrial or endoplasmic reticulum photodamage. Photochem. Photobiol 2007;83:1024-1028. [PubMed: 17880495]

Kessel D, Vicente MG, Reiners JJ Jr. Initiation of apoptosis and autophagy by photodynamic therapy. Lasers Surg. Med 2006;38:482-488. [PubMed: 16615135]

Kim HR, Luo Y, Li G, Kessel D. Enhanced apoptotic response to photodynamic therapy after Bcl-2 transfection. Cancer Res 1999;59:3429-3432. [PubMed: 10416606]

Klionsky D, et al. Guidelines for the use and interpretation of assays for monitoring autophagy in higher eukaryotes. Autophagy 2008;4:151-175. [PubMed: 18188003]

Lam M, Oleinick NL, Nieminen AL. Photodynamic therapy-induced apoptosis in epidermoid carcinoma cells: Reactive oxygen species and mitochondrial inner membrane permeabilization. J. Biol. Chem 2001;276:47379-47386. [PubMed: 11579101]

Mizushima N, Yoshimori T. How to interpret LC3 immunoblotting. Autophagy 2007;3:542-545. [PubMed: 17611390]

Ogata M, Hino S, Saito A, Morikawa K, Kondo S, Kanemoto S, Murakami T, Taniguchi M, Tanii I, Yoshinaga K, Shiosaka S, Hammarback JA, Urano F, Imaizumi K. Autophagy is activated for cell survival after endoplasmic reticulum stress. Mol. Cell. Biol 2006;26:9220-9231. [PubMed: 17030611]

Pattingre S, Tassa A, Qu X, Garuti R, Liang XH, Mizushima N, Packer M, Schneider MD, Levine B. Bcl-2 antiapoptotic proteins inhibit Beclin 1-dependent autophagy. Cell 2005;122:927-939. [PubMed: 16179260]

Pryde JG, Walker A, Rossi AG, Hannah S, Haslett C. Temperature-dependent arrest of neutrophil apoptosis. Failure of Bax insertion into mitochondria at 15 degrees $\mathrm{C}$ prevents the release of cytochrome c. J. Biol. Chem 2000;275:33574-33584. [PubMed: 10896657]

Reiners JJ Jr. Caruso JA, Mathieu P, Chelladurai B, Yin XM, Kessel D. Release of cytochrome c and activation of pro-caspase-9 following lysosomal photodamage involves Bid cleavage. Cell Death Differ 2002;9:934-944. [PubMed: 12181744]

Trivedi NS, Wang H-W, Nieminen AL, Oleinick NL, Izatt JA. Quantitative analysis of Pc 4 localization in mouse lymphoma cells via double-label confocal fluorescence microscopy. Photochem. Photobiol 2000;71:634-639. [PubMed: 10818795]

Usuda J, Chiu SM, Murphy ES, Lam M, Nieminen AL, Oleinick NL. Domain-dependent photodamage to Bcl-2: A membrane-anchorage region is needed to form the target of phthalocyanine photosensitization. J. Biol. Chem 2003;278:2021-2029. [PubMed: 12379660]

Uzdensky A, Juzeniene A, Ma LW, Moan J. Photodynamic inhibition of enzymatic detachment of human cancer cells from a substratum. Biochim. Biophys. Acta 2004;1670:1-11. [PubMed: 14729136] 
Xue LY, Chiu SM, Azizuddin K, Joseph S, Oleinick NL. The death of human cancer cells following photodynamic therapy: Apoptosis competence is necessary for Bcl-2 protection but not for induction of autophagy. Photochem. Photobiol 2007;83:1016-1023. [PubMed: 17880494]

Xue LY, Chiu SM, Oleinick NL. Photochemical destruction of the Bcl-2 oncoprotein during photodynamic therapy with the phthalocyanine photosensitizer Pc 4. Oncogene 2001a;20:3420 3427. [PubMed: 11423992]

Xue LY, Chiu SM, Oleinick NL. Photodynamic therapy-induced death of MCF-7 human breast cancer cells: a role for caspase-3 in the late stages of apoptosis but not for the critical lethal event. Exp. Cell Res 2001b;263:145-155. [PubMed: 11161713]

Wang Y, Singh R, Massey AC, Kane SS, Kaushik S, Grant T, Xiang Y, Cuervo AM, Czaja MJ. Loss of macroautophagy promotes or prevents fibroblast apoptosis depending on the death stimulus. J. Biol. Chem 2008;283:4766-4777. [PubMed: 18073215] 


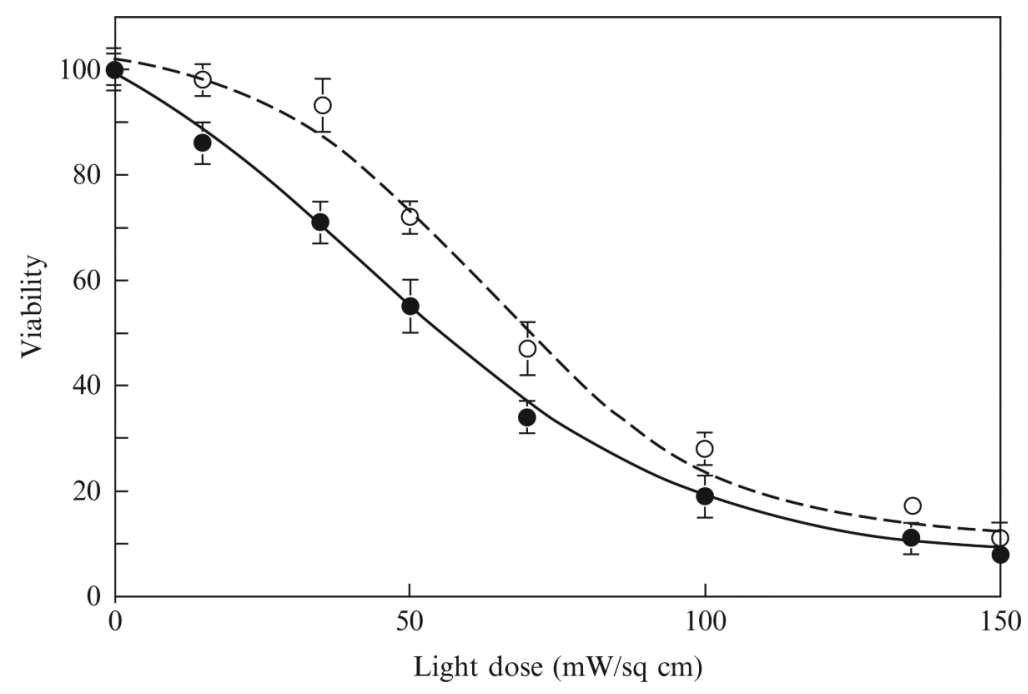

Figure 1.1.

Dose-response curve obtained with wild-type L1210 cells (dashed line) and an Atg7 knockdown subline (solid line). Cells were photosensitized with the porphycene CPO and the light dose was varied as indicated. Viability was assessed by clonogenic assays. 

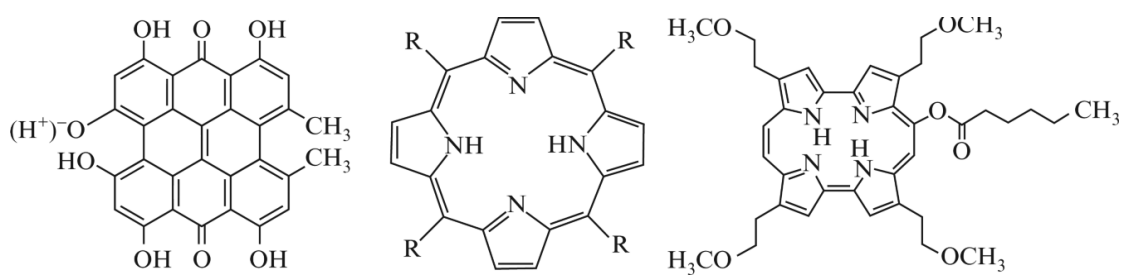

Figure 1.2.

Structure of some typical photosensitizing agents. From left: hypericin, the basic porphyrin ring structure and the porphycene termed $C P O$. 


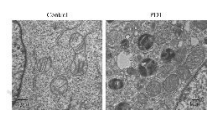

Figure 1.3.

Electron micrographs of untreated (left) and PDT-treated (right) MCF-7 cells. Note the presence of numerous autophagosomes after PDT, some containing what appear to be degraded mitochondria. 


\section{[.]}

Figure 1.4.

Progression of autophagy and apoptosis after photodynamic therapy. Murine leukemia L1210 cells were incubated for $30 \mathrm{~min}$ with a $2 \mu M$ concentration of the porphycene CPO, resuspended in fresh medium, irradiated $\left(135 \mathrm{~mJ} / \mathrm{cm}^{2}\right)$ with light $(600-640 \mathrm{~nm})$ at $10^{\circ} \mathrm{C}$, then warmed to $37^{\circ} \mathrm{C}$. Phase-contrast images were obtained at intervals. $(A)$ Before irradiation, $(B) 15$ min after irradiation, $(C)$ after $1 \mathrm{~h},(D)$ after $4 \mathrm{~h}$, and $(E)$ after $24 \mathrm{~h}$. 


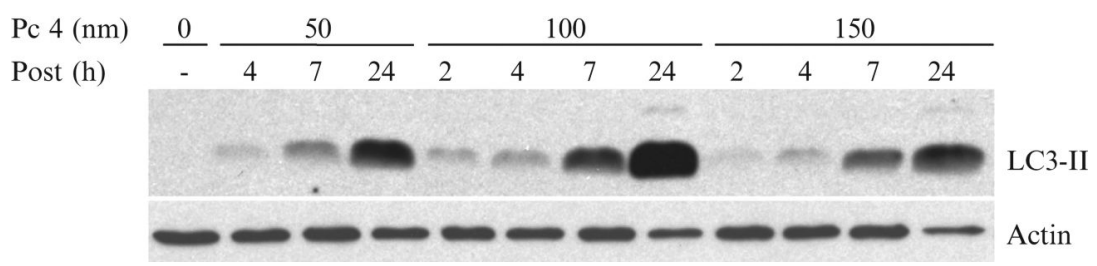

Figure 1.5.

Time-course and PDT dose-response for the accumulation of LC3-II in MCF-7c3 cells. Cells were exposed to the indicated concentrations of the photosensitizer PC 4 overnight, followed by photoirradiation with $200 \mathrm{~mJ} / \mathrm{cm}^{2}$ of red light from a light-emitting photodiode array. Cells were collected at the indicated times post-irradiation and analyzed on Western blots. 

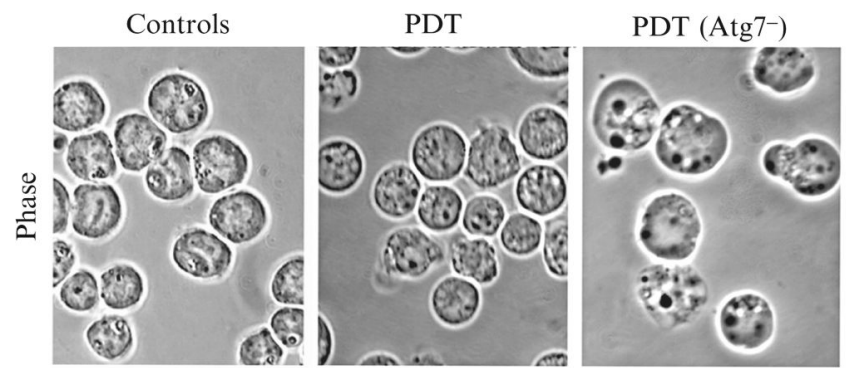

PDT $\left(\mathrm{Bax}^{-}\right)$
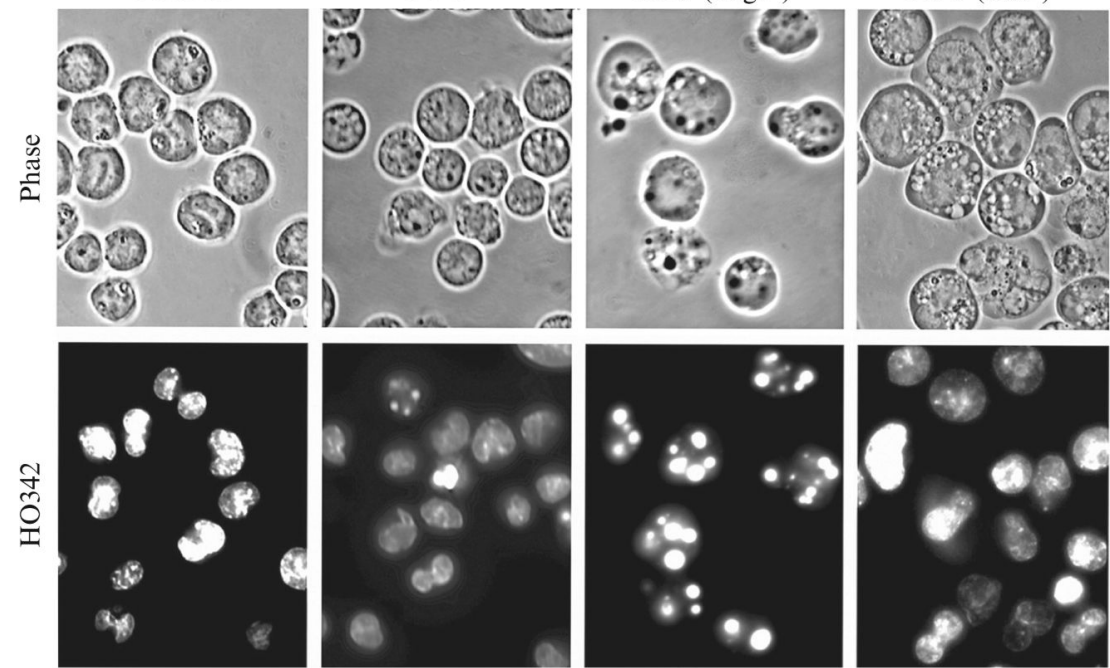

Figure 1.6.

Murine leukemia cells were photosensitized and irradiated as shown in Fig. 1.2. Phase-contrast (top) and fluorescence images after treatment with Höchst dye HO33342 [HO342] labeling (bottom) were obtained $1 \mathrm{hr}$ after a subsequent incubation at $37^{\circ} \mathrm{C}$. (A) L1210 controls, (B) L1210 + PDT, (C) L1210/Atg7 + PDT, (D) L1210/Bax + PDT. 
Table 1.1

Typical incubation conditions for photosensitizing agents

\begin{tabular}{|llll|}
\hline Sensitizer & Relative hydrophobicity & Concentration $(\boldsymbol{\mu M})$ & Time $(\mathbf{h})$ \\
CPO & moderate & 2 & 0.5 \\
NPe6 & very low & 30 & 16 \\
mTHPC & very high & $2-4$ & 16 \\
Pc 4 & high & 0.2 & $1-18$ \\
\hline
\end{tabular}

